\title{
Support Education Activity
}

National Cancer Institute

\section{Source}

National Cancer Institute. Support Education Activity. NCI Thesaurus. Code C162670.

Postoperative care consisting of 1) a supportive cancer-related education activity including a direct 10-15 minute phone conversation with a Registered Nurse researcher each week for 6-weeks after returning home from the hospital; 2 ) wear a pedometer each day of the study; 3) record pedometer steps in the daily diary each day. 